ARTIGO

\title{
ANÁLISE BIBLIOMÉTRICA DA REVISTA CONTROLE - DOUTRINA E ARTIGOS: período 2005 a 2016
}

\author{
BIBLIOMETRIC ANALYSIS OF THE JOURNAL CONTROL - DOCTRINE AND ARTICLES: \\ period 2005 to 2016
}

\author{
Josimar Batista dos Santos ${ }^{1}$ \\ Maria Amélia Holanda Cavalcante ${ }^{2}$
}

1 Mestre em História pela Pontifícia Universidade Católica do Rio Grande do Sul (PUC-RS). Chefe do Núcleo de Biblioteca e Documentação - Instituto Plácido Castelo (IPC) / Tribunal de Contas do Estado do Ceará (TCECE).

E-mail: josimar.batista@tce.ce.gov.br

${ }^{2}$ Especialista em Auditoria de Controle Externo pela Universidade Federal do Ceará (UFC).

E-mail: ameliahcavalcante@yahoo.com.br

\section{ACESSO ABERTO}

Copyright: Esta obra está licenciada com uma Licença Creative Commons Atribuição 4.0 Internacional. $(\mathrm{(c)}) \mathbf{B Y}$

Conflito de interesses: Os autores declaram que não há conflito de interesses.

Financiamento: Não há.

Declaração de Disponibilidade dos dados: Todos os dados relevantes estão disponíveis neste artigo.

Recebido em: 31/07/2018.

Revisado em: 09/11/2018.

Aceito em: 10/12/2018

\section{Como citar este artigo:}

SANTOS, Josimar Batista dos; CAVALCANTE, Maria Amélia Holanda. Análise bibliométrica da Revista Controle - doutrina e artigos: período 2005 a 2016. Informação em Pauta, Fortaleza, v. 3, n. 2, p. 73-98, jul./ago. 2018. DOI: https://doi.org/ 10.32810/25253468.ip.v3i2.2018.33227.73-98.

\section{RESUMO}

O objetivo do presente estudo foi realizar uma análise bibliométrica da Revista Controle, utilizando-se da lei bibliométrica de Zipf para a mensuração, bem como contribuir para a melhoria do periódico. Porquanto, a questão norteadora desta pesquisa foi investigar quais os parâmetros de publicação científica da Revista Controle - Doutrina e Artigos, através da análise bibliométrica. Para tanto, utilizou-se da estatística descritiva, com a representação dos dados em tabelas, por meio de indicadores selecionados, com método dedutivo, por meio de uma abordagem qualitativa e quantitativa, com o procedimento bibliográfico. Por fim, constatouse que a Revista Controle teve uma evolução significativa, à luz dos parâmetros analisados.

Palavras-chave: Periódicos científicos. Bibliometria. Lei de Zipf. Publicações científicas. Tribunal de Contas do Estado do Ceará.

\section{ABSTRACT}

The objective of the present study was to perform a bibliometric analysis of the Control Journal, using Zipf's bibliometric law for the measurement, as well as contribute to the improvement of the journal. Because, the guiding question of this research was to investigate the parameters of scientific publication of the Journal Control - Doctrine and Articles, through bibliometric analysis. To do so, we used descriptive statistics, with the representation of the data in tables, through 
selected indicators, with deductive method, through a qualitative-quantitative approach and with the bibliographic procedure. Finally, it was verified that the Control Journal had a significant evolution, in light of the parameters analyzed.
Keywords: Scientific Journals. Bibliometrics. Law Zipf's. Scientific publications. Court of Auditors of the State of Ceará.

\section{INTRODUÇÃO}

Ao longo da história, os registros da produção científica aumentaram significativamente, tornando o seu controle um processo que exigiu novos instrumentos para a sua mensuração. Durante esse caminho, os métodos matemáticos e estatísticos auxiliaram esse controle, que aliados às novas aéreas de estudo evoluíram para acompanhar os processos de divulgação científica. Um desses instrumentos é a bibliometria que no século XIX permitiu quantificar os processos da comunicação científica. Com o uso da bibliometria novos parâmetros foram investigados para monitorar as publicações científicas. Assim, passou-se a pesquisar os parâmetros de publicações, palavras-chave, usuários, autores, citações e periódicos.

Dessa forma, a decisão de eleger a Revista Controle: Doutrina e Artigos, que, desde o início, já publicava artigos de elevado nível acadêmico, e, progressivamente, foi se transformando em uma importante publicação científica nas áreas contempladas pelas Ciências Sociais Aplicadas, tais como: administração pública, direito público, entre outras, para realizar um estudo bibliométrico pela Lei de Zipf, foi impulsionada, portanto, pela necessidade de colocá-la sob mais um olhar, entre as múltiplas possibilidades de pesquisa, que ela adquiriu durante todos esses anos de circulação, elevando à categoria de um periódico de referência na temática do controle externo.

Este estudo tem como objetivo principal contribuir para a melhoria do periódico, permitindo que o mesmo seja, sucessivamente, melhor avaliado no sistema Qualis Periódicos da Coordenação de Aperfeiçoamento de Nível Superior (CAPES) e que os profissionais das áreas pertinentes disponham de mais um periódico de nível de qualidade incontestável. Dessa forma, a questão norteadora desta pesquisa foi: quais os parâmetros de publicação científica da Revista Controle - Doutrina e Artigos, através da análise bibliométrica? Para tanto, selecionou-se os seguintes objetivos específicos: mensurar o quantitativo de artigos, classificar os artigos por área de conhecimento, analisar as palavras-chave, conhecer os autores de artigos quanto à titulação e 
vinculação institucional e averiguar o número médio de páginas por artigo. À vista disto, conhecer melhor as particularidades da produção científica deste periódico no período de 2005 a 2016.

\section{REFERENCIAL TEÓRICO}

No presente tópico, buscou-se uma fundamentação teórica para o tema abordado. Por conseguinte, foram incluídos os itens a seguir, como resultado da revisão do estado da arte.

Dessa forma, o tópico 2 apresenta os seguintes itens: 2.1 Breve relato histórico: relata de forma metodológica a trajetória da Revista Controle; 2.2 Produção científica: apresenta as definições de produção científica e a importância da comunicação dessa informação científica para o desenvolvimento científico e tecnológico do país; 2.3 Canais da comunicação científica: registra os dois tipos de comunicação científica, os formais e informais; 2.4 Periódicos científicos: faz uma abordagem dos periódicos científicos, sua importância para a comunicação científica e a rápida difusão das informações; 2.5 Bibliometria: aborda como área de estudo da Ciência da Informação e sua estruturação por meio de processos técnicos definidos na análise da produção científica.

\subsection{Breve relato histórico}

A Revista Controle - Doutrina e Artigos, publicação oficial do Tribunal de Contas do Estado do Ceará (TCE-CE), foi criada em 1998, mediante decisão do então presidente, conselheiro Alexandre Figueiredo. A princípio, o objetivo da publicação consistiu em veicular informação com elevado nível de qualidade, bem como assegurar a disseminação do conhecimento técnico-científico do tribunal para a sociedade.

Cumpre ressaltar em sua trajetória de aprimoramento, que desde o dia 15 de setembro de 2006, a Revista Controle está registrada junto ao Instituto Brasileiro de Informação em Ciência e Tecnologia (IBICT), sendo identificada pelo código ISSN 1980086X para a versão impressa.

A partir desse momento, a Revista Controle assumiu um formato acadêmico, passando a ter publicações semestrais. Está classificada no sistema Qualis Periódicos da 
Coordenação de Aperfeiçoamento de Nível Superior (CAPES), conquistou recentemente a classificação B4 em Planejamento Urbano e Regional/Demografia e, posteriormente, na última avaliação de classificação de periódicos do quadriênio 2013-2016, avançou em termos de reconhecimento acadêmico ao receber a classificação B4, desta vez na área de Administração Pública e de Empresas, Ciências Contábeis e Turismo.

Além disso, no ano de 2017, a Revista Controle lançou sua versão eletrônica, utilizando a plataforma eletrônica do Open Journal System (OJS), customizada pelo Instituto Brasileiro de Informação em Ciência e Tecnologia (IBICT), para sua a administração e publicação. Nesse momento, registrou-se no Instituto Brasileiro de Informação em Ciência e Tecnologia (IBICT), com o ISSN-e 2525-3387, bem como incluída em bases de dados e diretórios nacionais e internacionais.

A Revista Controle, atualmente, está sob a coordenação do Presidente do TCE Ceará, Conselheiro Edilberto Carlos Pontes Lima, o qual é o Editor-Chefe e conta com um Conselho Editorial composto por membros com elevada titulação acadêmica.

Os temas abordados no periódico tratam das ramificações do Direito Constitucional, Direito Administrativo, Finanças Públicas, Controle Externo, Lei de Responsabilidade Fiscal (LRF), Lei de Licitações e Contratos, Fiscalização das Organizações Sociais, Processo Administrativo, Contabilidade Pública, Auditoria Operacional, de Gestão e de Processos, dentre outros assuntos afins.

\subsection{Produção científica}

A ciência evolui por meio de novas descobertas e, a produção de novos conhecimentos se dá com o registro e a divulgação dessa produção para o acesso de toda a comunidade científica. A definição de produção científica é "volume de documentos gerados, onde se encontram registradas e disseminadas as descobertas de uma área" (CUNHA; CAVALCANTI, 2008, p. 294).

Esses conhecimentos são de vital importância para o avanço de um país, nação ou sociedade, pois se pode tomar como medida o desenvolvimento de uma nação pelos aportes financeiros em pesquisas. Segundo Kuramoto (2006, p. 91), esclarece que "a informação científica é o insumo básico para o desenvolvimento científico e tecnológico de um país". 
Assim, fica evidente que os países mais desenvolvidos, certamente, possuem um maior investimento em pesquisas. Por outro lado, os países em desenvolvimento, ainda não conseguiram atingir os patamares necessários de aporte financeiro para área científica e tecnológica. Além disso, nesses países, provavelmente, os meios de comunicação científica são escassos e muitas das vezes deficientes. Para Kuramoto (2006, p. 91) “o acesso à informação científica tem sido um grande desafio para países em desenvolvimento como o Brasil".

$\mathrm{Na}$ busca de novas ferramentas de acesso ao conhecimento científico, surgiu em 2002, o movimento Open Access Iniciative (OAI), em Budapest. Kuramoto (2006, p. 154) assevera que "um cenário onde as barreiras que dificultam o acesso à literatura científica começam a serem derrubadas por intermédio de ações estratégicas propostas por esse movimento mundial". 0 referido movimento define então duas estratégias, uma chamada de via verde (autoarquivamento da publicação em repositórios de acesso livre) e a outra via dourada (publicação de artigos em periódicos de acesso livre).

Esse movimento busca uma maior interoperabilidade para o intercâmbio de informações científicas em formato digital, facilitando desta maneira o acesso e à difusão da produção científica em âmbito mundial. Essas ferramentas trazem novas possibilidades para a comunidade científica, ampliando os meios de comunicação científica. Portanto, “A comunicação científica pode ser considerada como um processo que envolve a construção, comunicação e uso do conhecimento científico para possibilitar a promoção de sua evolução." (WEITZEL, 2006, p. 88).

Todavia, nesse caminho entre a produção e o acesso à informação científica, o processo de comunicação torna-se o elo entre o pesquisador e a sociedade. Nota-se aqui que o cientista necessita externalizar sua produção científica, pois caso não chegue aos seus interessados diretos, torna-se inócua, ou seja, a sua difusão é o mecanismo de geração de novos conhecimentos. Nesse sentido, a comunicação científica é relatada por Cunha e Cavalcanti (2008, p. 97) como um "conceito proposto por John Bernal, no final dos anos trinta, para designar o processo específico de produção, consumo e transferência de informação no campo científico".

Desta forma, a disseminação do conhecimento científico é materializada com as publicações das pesquisas realizadas pelos estudiosos das diversas áreas do conhecimento. A aceitação da literatura científica pelos pares, para a fundamentação 
teórica de novas descobertas, é um elemento primordial para ciência. Segundo Davyt e Velho (2000),

Este processo tem sido, genericamente, denominado de revisão por pares ou julgamento por pares (peer review). Apesar do nome comum, e de sempre envolver, de alguma maneira, a opinião de um par, o julgamento por pares, na realidade, não é um procedimento único e envolve uma enorme gama de formas institucionais. Estas, como já apontado, certamente refletem características do contexto histórico e social onde o processo se realiza.

Verifica-se, assim, que o processo de comunicação científica é de fundamental importância para o avanço da ciência, sem ele a disseminação das nossas descobertas científicas, o conhecimento ficaria restrito ao universo do pesquisador. Além disso, Menzel em 1958 sinalizou as funções da comunicação científica na ciência, explicitado por Kaplan e Storer (1968 apud TARGINO, 2000, p. 10):

\footnotetext{
a) fornecer respostas a perguntas específicas;

b) concorrer para atualização profissional do cientista no campo específico de sua atuação;

c) estimular a descoberta e a compreensão de novos interesses;

d) divulgar as tendências de áreas emergentes, fornecendo aos cientistas ideia da relevância do seu trabalho;

e) testar a confiabilidade de novos conhecimentos, diante da possibilidade de testemunhos e verificações;

f) redirecionar ou ampliar o rol de interesse dos cientistas;

g) fornecer feedback para o aperfeiçoamento da produção do pesquisador.
}

\subsection{Canais de comunicação científica}

Os canais de divulgação da produção científica evoluíram ao longo do tempo, passando dos meios de produção tradicionais tipográficos para a informação digital. Eles se estruturam basicamente em dois tipos, que são: “Os canais informais, também chamados de "comunicação informal" e canais formais - "comunicação formal." (MUELLER, 2000).

Essa classificação dos canais de comunicação científica em informais e formais leva-se em consideração os meios de comunicação das pesquisas. Assim sendo, os canais formais são registrados e comunicados pelos meios tradicionais, ou seja, são fontes escritas. Portanto, tem o acesso aos documentos originais e já citados. Segundo Targino (2000, p. 19),

Em se tratando da comunicação científica formal, esta se dá através de diversos meios de comunicação escrita, com destaque para livros, periódicos, 
obras de referência em geral, relatórios técnicos, revisões de literatura, bibliografias de bibliografias etc. [...] (grifo do autor).

Registra-se que os meios de comunicação formais, são os mais importantes para a disseminação do conhecimento científico. Eles, geralmente, atingem um público mais abrangente, devido ao fato que os meios de comunicação são estruturados para esse tipo de informação. Nesse sentido, Mueller (2000, p. 22, grifo nosso) ressalta que dentre esses canais formais, "o mais importante para a ciência são os artigos publicados em periódicos científicos".

Por outro lado, o processo de comunicação científica informal se dá de forma direta, por meio de relações interpessoais e de eventos da área do pesquisador. Essa comunicação oral, tanto pública quanto privada, registrada ou não, tem como principal característica uma maior rapidez de disseminação da comunicação científica.

A comunicação científica informal consiste na utilização de canais informais, em que a transferência da informação ocorre através de contatos interpessoais e de quaisquer recursos destituídos de formalismo, como reuniões científicas, participação em associações profissionais e colégios invisíveis. É a comunicação direta pessoa a pessoa (TARGINO, 2000, p. 19-20).

A origem da fonte pesquisada, ou seja, qual o acesso ao documento ou informação produzida, compreende outro aspecto a ser analisado no processo da comunicação científica. Eles podem ser classificados em três categorias:

a) Documentos primários - Documentos primários são geralmente aqueles produzidos com a interferência direta do autor da pesquisa. Considerando o contínuo do modelo de Garvey e Griffith, estariam principalmente no início do processo, incluindo, por exemplo, relatórios técnicos, trabalhos apresentados em congressos, teses e dissertações, patentes, normas técnicas e o artigo científico.

b) Documentos secundários - que têm justamente a função de facilitar o uso do conhecimento disperso nas fontes primárias. As fontes secundárias apresentam a informação filtrada e organizada de acordo com um arranjo definido, dependendo de sua finalidade. São representadas, por exemplo, pelas enciclopédias, dicionários, manuais, tabelas, revisões da literatura, tratados, certas monografias e livros-texto, anuários e outras.

c) Documentos terciários - são aquelas que têm a função de guiar o usuário para as fontes primárias e secundárias. São as bibliografias, os serviços de indexação e resumos, os catálogos coletivos, os guias de literatura, os diretórios e outras. Após a publicação do artigo relatando a pesquisa em periódico científico, são principalmente as fontes secundárias e terciárias que ocorrem no contínuo do fluxo (MULLER, 2000, p. 31).

Os documentos primários são o principal documento utilizado pelo pesquisador, em que tem acesso direto à fonte do autor consultado. Portanto, são informações 
publicadas pelo autor, tanto, por meio da comunicação formal, quanto, da comunicação informal. Seguidamente, os documentos secundários direcionam os usuários para as fontes primárias ou originais, ou seja, reunidos, selecionados, sintetizados ou reagrupados para fins específicos por tema ou área de conhecimento. Por último, as fontes terciárias, que são documentos compilados de fontes primárias e secundárias. Elas, geralmente, são conhecidas como obras de referências.

\subsection{Periódicos científicos}

Os periódicos são publicações seriadas, publicadas com uma periodicidade regular, com um título único, por um período indefinido e com uma numeração sequencial. Os periódicos científicos são registrados pelo título, com um número único, o ISSN, registrado no Brasil pelo IBICT que tem a função de Centro Nacional da Rede ISSN.

Os primeiros registros de periódicos científicos são do século XVII, na Europa, mais especificamente na França e na Inglaterra. Primeiramente, na França, aparece o primeiro periódico científico, Le Journal des Sçavant, fundado em 5 de janeiro de 1665, na capital francesa, Paris, pelo advogado e membro do parlamento Denis de Sallo. Posteriormente, denominado de Le Journal des Savants (SPINAK; PACKER, 2015). 0 periódico possuía um plo, “[...] a revista tinha como funções catalogar e reunir os livros mais importantes publicados na Europa; publicar óbitos de personalidades eminentes, descrever os progressos científicos e técnicos, registrar as principais decisões jurídicas e publicar notícias sobre o que acontecia na "República das Letras" (RUSSO; SANTOS; SANTOS, 2001, p. 2).

Mais tarde, outro periódico que se destaca é o Philosophical Transactions, na Ingralterra. Publicado, posteriormente, 60 dias após o Journal des Sçavant, também em 1665, em Londres, o Philosophical Transactions: giving some Accompt of the present Undertakings, Studies and Labours of the Ingenious in many considerable parts of the World, editado pela Royal Society. Portanto,

As Philosophical Transactions em comparação ao Journal des Sçavans (com seus cinco objetivos ambiciosos), cobria uma faixa mais reduzida de temas, principalmente os que hoje poderíamos considerar "científicos", e relativamente poucas revisões de livros" (SPINAK; PACKER, 2015). 
Percebe-se que, no início, os periódicos científicos registravam, além de novas ideias e descobertas científicas, outros temas correlatos às ciências, aos autores e às informações técnicas e jurídicas. Contudo, seu enfoque sempre se direcionou ao progresso da ciência e suas transformações.

No Brasil, as publicações de periódicos científicos são registradas alguns séculos posteriormente. Há registros das primeiras publicações no século XIX. Conforme Souza (2006, p. 25),

No Brasil, os periódicos científicos começaram a surgir em meados do século XIX, ou seja, dois séculos após o aparecimento dos exemplares europeus. A primeira publicação foi a Gazeta Médica do Rio de Janeiro, criada em 1862 e, a seguir, surgiu a Gazeta Médica da Bahia, em 1866. Entretanto, a primeira revista regularmente publicada no Brasil, em 1917, foram os Anais da Academia de Ciências, com o nome de Revista da Sociedade Brasileira de Ciências.

Esse tipo de publicação, na maioria das vezes, são publicações de instituições acadêmicas, em que publicam artigos dos resultados das suas pesquisas realizadas. Segundo explica Souza e Costa (2017, p. 917), os periódicos são de “[...] fundamental importância, pois são constituídos por novas informações, sendo indispensáveis para o resultado de pesquisas, novas interpretações de teorias ou novos acontecimentos, favorecendo a comunicação científica e a rápida difusão das informações".

Igualmente, evidenciam que os periódicos científicos são uma fonte essencial para a divulgação do conhecimento científico. Isso, devido a sua natureza, por ser um meio de veiculação de novos conhecimentos, de periodicidade menor, com um amplo alcance. Nota-se, que desde o início, o periódico científico tornou-se o principal meio de comunicação da ciência.

A academia científica já consolidou esse meio de comunicação, haja vista que sua abrangência é cada vez maior entre a comunidade científica. Resulta que com a evolução dos meios de comunicação, ele também evoluiu para outros formatos. Hoje, seu maior meio de distribuição é o formato eletrônico.

Nesse caminho de divulgação do conhecimento científico, esse formato se ampliou devido ao fato da sua amplitude espaço-temporal. Uma vez rompidas às barreiras do tempo e espaço, tornou a divulgação dessas pesquisas instantâneas. Isso é uma marca do conhecimento científico, ele precisa ser acessado por uma comunidade cada vez maior. No que concerne às publicações de trabalhos científicos, 
0 registro da ciência é essencial à conservação e preservação de resultados, observações, cálculos, teorias, etc., possibilitando, assim, a crítica, aceitação ou não e aperfeiçoamentos posteriores. Entretanto, a comunicação desses registros é ação ainda mais importante, condição pela qual se possibilita o alcance público, permitindo, assim, a apropriação desses por outros indivíduos e, consequentemente, a geração de mais conhecimentos (DROESCHER; SILVA, 2014, p. 171).

Outro ponto a ser considerado fundamental nessa evolução é o acesso livre a esse conhecimento. Além do acesso eletrônico, ele também passou a ser disponibilizado de forma universal, gratuita, com o seu conteúdo na íntegra, ou seja, o seu texto completo. Conforme Baptista et al. (2007, p. 5),

Acesso Livre diz respeito à acessibilidade ampla e irrestrita a conteúdos disponíveis em formato digital, no sentido em que remove barreiras de preço e de permissão, tornando a literatura científica disponível com o mínimo de restrições de uso.

Registra-se que a Revista Controle seguindo esse movimento do livre acesso, disponibiliza todo seu conteúdo de maneira eletrônica, sem barreiras de lugar e espaço, sem custo, universalizando o conhecimento da temática do controle externo.

\subsection{Bibliometria}

A análise de medição do conhecimento científico pode ser realizada utilizando diferentes técnicas estatísticas de mensuração da atividade científica. As técnicas quantitativas podem ser avaliadas, de acordo com Vanti (2002, 2010), através da bibliometria, cienciometria, informetria, webmetria, cibermetria e mais recentemente a altmetria. Cada qual propõe medir a divulgação do conhecimento científico e o fluxo da informação em aspectos diferentes de um determinado corpus do conhecimento.

A bibliometria, como área de estudo da ciência da informação, busca mensurar a comunicação escrita nos seus mais variados meios de comunicação. Os seus precursores foram Hulme (1922) - estatística bibliográfica, Otlet (1934) - Le livre et la mesure, Bibliométrie e Pritchard (1969) - "Statistical bibliography or bibliornetrics?. Para Paul Otlet, a bibliometria é definida como "a parte da bibliologia que trata da medida ou quantidade aplicada aos livros" (CUNHA, CAVALCANTI, 2008, p. 48).

0 estudo da bibliometria vem estabelecer leis que permitam a análise da literatura científica com parâmetros já validados pela ciência. Destacam-se as três 
principais leis da bibliometria que são Bradfort, Lotka, Zipf. Alvarado (1984, 91), as descrimina como: "1. A Lei de Bradford, que descreve a distribuição da literatura periódica numa área específica; 2. A Lei de Lotka, que descreve a produtividade dos autores; e 3. A Lei de Zipf, que descreve a frequência no uso de palavras num determinado texto".

Nesse sentido, a Lei de Bradford, analisa a dispersão dos artigos científicos relevantes num conjunto de publicações de áreas dispersas do conhecimento. 0 principal aspecto da Lei de Bradford é evidenciar quais são os periódicos que concentram os artigos mais relevantes de determinada área. Em seguida, a Lei de Lotka, é mediar a produtividade dos autores, e suas contribuições para a ciência. Por fim, a Lei de Zip, as ocorrências dos termos mais utilizados nos trabalhos publicados.

Com essas leis bibliométricas, a comunidade acadêmica passou a utilizar esses instrumentos para medir as publicações científicas e os impactos desse conhecimento registrado. Segundo Bressane e Ohira (2007, p. 7), “a partir da década de 1960 encontram-se na literatura estudos sobre avaliações de periódicos técnico-científicos que apontam para a necessidade de se definir parâmetros mensuráveis, que possam refletir a qualidade da informação registrada".

Além desses estudos bibliométricos citados, alguns estudos utilizam-se da Lei de Elitismo de Price. A referida lei estuda os autores mais produtivos em determinada área do conhecimento. De acordo com Cunha e Cavalcanti (2008, p. 221), a Lei de Price "Afirma que metade dos artigos publicados sobre determinado assunto foi produzida por autores que consistiam aproximadamente na raiz quadrada do total de autores daquela área".

No Brasil, os estudos da bibliometria iniciam-se, na década de 70, pelo antigo Instituto Brasileiro de Bibliografia e Documentação (IBBD), atualmente, Instituto Brasileiro de Informação em Ciência e Tecnologia (IBICT), sendo que as pesquisas abrangiam várias áreas do conhecimento científico.

A bibliometria, como estudo quantitativo da comunicação escrita, estrutura-se por meio de processos técnicos definidos na análise da produção científica.

Sinteticamente, podem ser destacados alguns procedimentos percebidos como essenciais aos estudos bibliométricos: definição do corpus empírico; identificação das fontes de informação; definição da cadeia de análise e os elementos bibliográficos a serem considerados no estudo (processos e técnicas); acesso e recuperação de referências bibliográficas; tratamento de dados bibliográficos para fins de análise bibliométrica; análises e validação de 
resultados; representação gráfica dos dados obtidos e relatórios atualizados (KOBASHI; SANTOS, 2008 apud SOLANO; GUERRA, 2014, p. 2).

Tendo em vista a aplicabilidade das leis bibliométricas com seus procedimentos, serão analisados os parâmetros definidos para apontar os indicadores bibliométricos na Revista Controle.

\section{RESULTADOS DA ANÁLISE BIBLIOMÉTRICA DA REVISTA CONTROLE}

Neste tópico, são apresentadas as análises dos dados coletados durante a realização da pesquisa, com base nos indicadores selecionados:

A pesquisa foi realizada com os seguintes objetivos específicos:

1) mensurar o quantitativo de artigos nos anos de 2005 a 2016, por volume, número e ano de publicação;

2) classificar os artigos por área de conhecimento;

3) descobrir quais as palavras-chave mais utilizadas pelos autores dos artigos;

4) conhecer os autores de artigos, titulação e vinculação institucional;

6) averiguar o número médio de páginas por artigo.

A Revista Controle publicou 1 volume, no período de 2005 a 2007, no ano de 2008 não foi publicado nenhum volume e, de 2009 a 2016, exceto no ano de 2010, foram publicados 2 volumes por ano, os quais totalizaram 307 artigos distribuídos em 18 volumes até o ano de 2016. A média anual de publicações no período foi de aproximadamente 26 artigos. Verificou-se que houve um crescimento de $450 \%$ no número de publicações, considerando-se o menor número (6) referente ao ano de 2005, em relação ao maior (27) referente ao ano de 2009. Considerando o número mínimo de 14 artigos na avaliação ${ }^{1}$ da área de Direito, verifica-se que não atendem esse requisito, somente, as edições 2005 (v. 5, n. 2), 2006 (v. 6, n. 1), 2016 (v. 14, n. 1) e (v. 14, n. 2). Esses números evidencia que a tendência da aceitação do periódico na área científica, faz com que consiga atrair mais submissões. Conforme se vê na Tabela 1.

\footnotetext{
1 Realizada pela Coordenação de Aperfeiçoamento de Pessoal de Nível Superior (CAPES), na qual avalia os programas de pós-graduação stricto sensu em funcionamento no Sistema Nacional de Pós-Graduação (SNPG).
} 
Tabela 1 - Distribuição de edições, quantidade de artigos por volume e número.

\begin{tabular}{|c|c|c|c|c|}
\hline ANO, VOL. E NUM. & QTDDE. & \% POR NUM. & \% POR VOL. & $\%$ POR ANO \\
\hline 2005, v. 5, n. 2 & 6 & $1,95 \%$ & $1,95 \%$ & $1,95 \%$ \\
\hline 2006, v. 6, n. 1 & 8 & $2,60 \%$ & \multirow{2}{*}{$7,16 \%$} & $2,60 \%$ \\
\hline 2007, v. 6, n. 2 & 14 & $4,56 \%$ & & $4,56 \%$ \\
\hline 2009, v. 7, n. 1 & 27 & $8,79 \%$ & \multirow{2}{*}{$15,30 \%$} & \multirow{2}{*}{$15,30 \%$} \\
\hline 2009, v. 7, n. 2 & 20 & $6,51 \%$ & & \\
\hline 2010, v. 8, n. 1 & 23 & $7,49 \%$ & $7,49 \%$ & $7,49 \%$ \\
\hline 2011, v. 9, n. 1 & 21 & $6,84 \%$ & \multirow{2}{*}{$13,02 \%$} & \multirow{2}{*}{$13,02 \%$} \\
\hline 2011 , v. 9, n. 2 & 19 & $6,18 \%$ & & \\
\hline 2012 , v. 10, n. 1 & 21 & $6,84 \%$ & \multirow{2}{*}{$13,02 \%$} & \multirow{2}{*}{$13,02 \%$} \\
\hline 2012 , v. 10, n. 2 & 19 & $6,18 \%$ & & \\
\hline 2013, v. 11 , n. 1 & 20 & $6,51 \%$ & \multirow{2}{*}{$12,05 \%$} & \multirow{2}{*}{$12,05 \%$} \\
\hline 2013 , v. 11, n. 2 & 17 & $5,53 \%$ & & \\
\hline 2014 , v. 12, n. 1 & 16 & $5,21 \%$ & \multirow{2}{*}{$11,07 \%$} & \multirow{2}{*}{$11,07 \%$} \\
\hline 2014, v. 12, n. 2 & 18 & $5,86 \%$ & & \\
\hline 2015, v. 13, n. 1 & 19 & $6,18 \%$ & \multirow{2}{*}{$11,07 \%$} & \multirow{2}{*}{$11,07 \%$} \\
\hline 2015. v. 13, n. 2 & 15 & $4,88 \%$ & & \\
\hline 2016, v. 14, n. 1 & 11 & $3,58 \%$ & \multirow{2}{*}{$7,81 \%$} & \multirow{2}{*}{$7,81 \%$} \\
\hline 2016, v. 14, n. 2 & 13 & $4,23 \%$ & & \\
\hline
\end{tabular}

Fonte: Elaborada pelos autores.

A Tabela 2 foi elaborada categorizando os artigos por área de conhecimento, o que permitiu evidenciar que dos 307 artigos publicados na Revista Controle, 39,41\% estão categorizados na área de conhecimento "Administração Pública"; enquanto $30,61 \%$ do total de artigos estão categorizados na área de conhecimento "Direito Público", totalizando um percentual de 70,02\%, permitindo visualizar as áreas de conhecimento mais privilegiadas no período de 2005 a 2016. Contudo, outra área do conhecimento a se destacar é a de economia, com 2,29\%; logo, em seguida a de serviços urbanos e regionais com 1,95\%. Todavia, deve-se ressaltar que um total de $76,22 \%$ dos artigos está categorizado na grande área "Ciências Sociais Aplicadas", permitindo retratar que as temáticas publicadas são condizentes com a área de atuação do periódico, visto que sua linha editorial concebe um perfil das áreas publicadas, as quais devem ser observadas.

A classificação nas áreas do conhecimento, levou-se em conta a análise dos títulos, resumos e das palavras-chaves dos artigos, considerando que somente um critério não seria suficiente para esse enquadramento. 
Tabela 2 - Categorização dos artigos por área de conhecimento.

\begin{tabular}{|c|c|c|}
\hline ARE A DE CONHE CIME NTO & QTDE.POR ARTIGO & PORCE NTAGEM \\
\hline $\begin{array}{c}\text { 6.02.02.00-9 Administração } \\
\text { Pública }\end{array}$ & 121 & $39,41 \%$ \\
\hline 6.01.02.00-4 Direito Público & 94 & $30,61 \%$ \\
\hline $\begin{array}{c}\text { 6.05.03.01-7 Serviços Urbamos e } \\
\text { Regionais }\end{array}$ & 6 & $1,95 \%$ \\
\hline $\begin{array}{l}\text { 1.03.03.00-6 Metodologia e } \\
\text { técnicas da computação }\end{array}$ & 4 & $1,30 \%$ \\
\hline $\begin{array}{l}6.03 .03 .00-0 \text { Economia } \\
\text { Monetária e Fiscal }\end{array}$ & 4 & $1,30 \%$ \\
\hline 6.01.00.00-1 Teoria do Direito & 3 & $0,98 \%$ \\
\hline 6.01.03.00-0 Direito Privado & 2 & $0,65 \%$ \\
\hline $\begin{array}{c}\text { 7.09.03.00-0 Comportamento } \\
\text { Político }\end{array}$ & 2 & $0,65 \%$ \\
\hline $\begin{array}{c}\text { 1.03.04.00-2 Sistemas de } \\
\text { computação }\end{array}$ & 1 & $0,33 \%$ \\
\hline $\begin{array}{c}\text { 6.02.03.00-5 Administração de } \\
\text { setores Especificos }\end{array}$ & 1 & $0,33 \%$ \\
\hline $\begin{array}{c}\text { 6.03.02.00-3 Métodos } \\
\text { Quantitativos em Economia }\end{array}$ & 1 & $0,33 \%$ \\
\hline $\begin{array}{c}\text { 6.03.04.00-6 Crescimento, } \\
\text { Flutuações, e Plan ejam ento } \\
\text { Econômico }\end{array}$ & 1 & $0,33 \%$ \\
\hline 6.07.03.00-8 Arquivologia & 1 & $0,33 \%$ \\
\hline $\begin{array}{c}\text { 7.08.04.00-1 Ensino- } \\
\text { Aprendizagem }\end{array}$ & 1 & $0,33 \%$ \\
\hline Não categorizada & 65 & $21,17 \%$ \\
\hline
\end{tabular}

Fonte: Elaborada pelos autores.

Os 307 artigos selecionados têm 1085 palavras-chave, ou seja, uma média de 3,53 palavras-chave por artigo. Considerando que um total de 56 artigos não apresentaram palavras-chave, deve-se ressaltar que a média de 4,32 palavras-chave foi obtida levandose em conta o total de 251 artigos que apresentaram palavras-chave, conforme se vê na Tabela 3. Também ocorreu a transformação das palavras-chave pluralizadas para o singular. 
Tabela 3 - Frequência das palavras-chave

\begin{tabular}{|c|c|c|c|c|c|}
\hline Palavras-chave & $\begin{array}{l}\text { Quantidade } \\
\text { de artigos }\end{array}$ & $\begin{array}{l}\text { Quantidade de } \\
\text { palavras-chave }\end{array}$ & $\begin{array}{l}\text { Frequênci } \\
\text { a de } \\
\text { repetição }\end{array}$ & $\begin{array}{l}\text { Frequência relativa } \\
\text { (\%) em relação à } \\
\text { quantidade de artigos }\end{array}$ & $\begin{array}{c}\text { Frequência relativa }(\%) \\
\text { em relação à quantidade } \\
\text { de palavras-chave }\end{array}$ \\
\hline 1.Tribunais de Contas & 307 & 1085 & 34 & 11,07 & 3,13 \\
\hline 2.Administração Pública & 307 & 1085 & 19 & 6,18 & 1,75 \\
\hline 3. Controle Externo & 307 & 1085 & 14 & 4,56 & 1,29 \\
\hline 4. Lei de Responsabilidade Fiscal & 307 & 1085 & 14 & 4,56 & 1,29 \\
\hline 5. Transparência & 307 & 1085 & 13 & 4,23 & 1,19 \\
\hline 6. Constituição & 307 & 1085 & 10 & 3,25 & 0,92 \\
\hline 7. Licitação & 307 & 1085 & 10 & 3,25 & 0,92 \\
\hline 8. Gestão de Pessoas & 307 & 1085 & 9 & 2,93 & 0,82 \\
\hline 9. Controle & 307 & 1085 & 9 & 2,93 & 0,82 \\
\hline 10. Controle Social & 307 & 1085 & 8 & 2,60 & 0,73 \\
\hline 11. Fiscalização & 307 & 1085 & 8 & 2,60 & 0,73 \\
\hline 12. Eficiência & 307 & 1085 & 7 & 2,28 & 0,64 \\
\hline 13. Democracia & 307 & 1085 & 7 & 2.28 & 0,64 \\
\hline 14. Gestão Pública & 307 & 1085 & 6 & 1,95 & 0,55 \\
\hline 15. Segurança Pública & 307 & 1085 & 6 & 1,95 & 0,55 \\
\hline 16. Serviço Público & 307 & 1085 & 6 & 1,95 & 0,55 \\
\hline 17. Controle Interno & 307 & 1085 & 5 & 1,62 & 0,46 \\
\hline 18. Contrato Administrativo & 307 & 1085 & 5 & 1,62 & 0,46 \\
\hline 19. Municípios & 307 & 1085 & 5 & 1,62 & 0,46 \\
\hline 20.Auditoria & 307 & 1085 & 4 & 1,30 & 0,36 \\
\hline 21. Cidadania & 307 & 1085 & 4 & 1,30 & 0,36 \\
\hline 22.Comissão Gestora & 307 & 1085 & 4 & 1,30 & 0,36 \\
\hline 23. Competência & 307 & 1085 & 4 & 1,30 & 0,36 \\
\hline 24. Corrupção & 307 & 1085 & 4 & 1,30 & 0,36 \\
\hline 25. Finanças Públicas & 307 & 1085 & 4 & 1,30 & 0,36 \\
\hline 26. Orçamento Participativo & 307 & 1085 & 4 & 1,30 & 0,36 \\
\hline 27. Orçamento Público & 307 & 1085 & 4 & 1,30 & 0,36 \\
\hline 28. Participação & 307 & 1085 & 4 & 1,30 & 0,36 \\
\hline 29.Prestação de Contas & 307 & 1085 & 4 & 1,30 & 0,36 \\
\hline 30. Políticas Públicas & 307 & 1085 & 4 & 1,30 & 0,36 \\
\hline 31. Participação & 307 & 1085 & 4 & 1,30 & 0,36 \\
\hline 31. Responsabilidade Fiscal & 307 & 1085 & 4 & 1,30 & 0,36 \\
\hline 32. Tribunal de Contas do Ceará & 307 & 1085 & 4 & 1,30 & 0,36 \\
\hline 33. Educação & 307 & 1085 & 3 & 0,97 & 0,27 \\
\hline 34. Efetividade & 307 & 1085 & 3 & 0,97 & 0,27 \\
\hline $\begin{array}{l}\text { 35. Equilibrio Econômico - } \\
\text { Financeiro }\end{array}$ & 307 & 1085 & 3 & 0,97 & 0,27 \\
\hline 36. Constitucionalidade & 307 & 1085 & 3 & 0,97 & 0,27 \\
\hline 37. Direitos Fundamentais & 307 & 1085 & 3 & 0,97 & 0,27 \\
\hline 38. Descentralização fiscal & 307 & 1085 & 3 & 0,97 & 0,27 \\
\hline 39. Capacitação & 307 & 1085 & 3 & 0,97 & 0,27 \\
\hline 40.Auditoria Governamental & 307 & 1085 & 3 & 0,97 & 0,27 \\
\hline 41. Legalidade & 307 & 1085 & 3 & 0,97 & 0,27 \\
\hline 42. Metas & 307 & 1085 & 3 & 0,97 & 0,27 \\
\hline 43. Participação Popular & 307 & 1085 & 3 & 0,97 & 0,27 \\
\hline 44. Administrativa & 307 & 1085 & 3 & 0,97 & 0,27 \\
\hline 45. Pregão Eletrônico & 307 & 1085 & 3 & 0,97 & 0,27 \\
\hline 46. Processo Administrativo & 307 & 1085 & 3 & 0,97 & 0,27 \\
\hline 47. Regulação & 307 & 1085 & 3 & 0,97 & 0,27 \\
\hline 48. Sociedade & 307 & 1085 & 3 & 0,97 & 0,27 \\
\hline 49. Jurisdição & 307 & 1085 & 3 & 0,97 & 0,27 \\
\hline 50. Estado & 307 & 1085 & 3 & 0,97 & 0,27 \\
\hline 51. Política & 307 & 1085 & 3 & 0,97 & 0,27 \\
\hline vezes & 307 & 1085 & 76 & 24,75 & 7 \\
\hline 53. Palavra chave repetida $1 \mathrm{vez}$ & 307 & 1085 & 640 & 208,46 & 58,98 \\
\hline
\end{tabular}

Fonte: Elaborada pelos autores. 
As palavras-chave dos artigos selecionados foram ordenadas pelo critério de número de vezes que foram repetidas em ordem decrescente. Conforme se vê na Tabela 3, foram apresentadas as frequências relativas das palavras-chave repetidas em relação ao total de artigos, o que permite estabelecer uma correlação entre as palavras-chave e a tipologia da Revista Controle. O resultado demonstra, em relação ao perfil editorial, coerência com os temas publicados.

Nesse ínterim, a Revista Controle, vem dentro da sua linha editorial publicando os manuscritos condizentes a sua área de atuação. Nota-se uma predominância da temática Tribunais de Contas com 11,07\%, fato que revela alto grau de assertividade temática. Logo, em seguida, aparece o tema da administração pública, com 6,18\%, reafirmando sua proposta editorial nesse campo do conhecimento. $\mathrm{Na}$ sequência, respectivamente, os assuntos: controle externo e lei de responsabilidade fiscal com 4,56\%, termos pertinentes aos tribunais de contas; transparência com 4,23\%, temática na ordem do dia nas instituições públicas; constituição e licitação com 3,25\%, assuntos afetos ao direito público e administração pública; gestão de pessoas e controle com 2,93\%, o primeiro assunto ligado à temática comum as instituições e outro voltado para a atividade-fim dos tribunais de contas; controle social e fiscalização com 2,60\%, temas importantes na sociedade contemporânea; eficiência e democracia com 2,28\%, termos que os cidadãos exigem que as instituições públicas as cumpram; gestão pública, segurança pública e serviço público com 1,95\%, o primeiro é um assunto amplo que aborda os outros dois; controle interno, contrato administrativo e municípios com 1,62\%, tem relação direta com a área de atuação do publicador; auditoria, cidadania, comissão gestora, competência, corrupção, finanças públicas, orçamento participativo, orçamento público, participação, prestação de contas, políticas públicas, participação, responsabilidade fiscal e Tribunal de Contas do Ceará com 1,30\%, refletem particularidades do todo; educação, efetividade, equilíbrio econômico-financeiro, constitucionalidade, direitos fundamentais, descentralização fiscal, capacitação, auditoria governamental, legalidade, metas, participação popular, administrativa, pregão eletrônico, processo administrativo, regulação, sociedade, jurisdição, estado e política com $0,97 \%$, são assuntos específicos com alguma relação dos termos anteriores; já as palavras-chave com frequência de duas vezes com 7\%, não configurou-se importante para a análise devido a sua dispersão; por fim, os assuntos que se repetiram 
uma vez obteve um percentual considerável de 58,98\%, fato que permite inferir que muitas das palavras-chave são usadas aleatoriamente.

Evidencia-se nesses dados que os assuntos com maiores incidências são diretamente afetas, as duas grandes áreas do conhecimento: administração pública e direito público. Assim sendo, permite-se aferir que o periódico tem uma política editorial criteriosa. Portanto, percebe-se a busca de um patamar de elevado nível editorial.

Sabe-se que a análise de assunto é complexa, que envolve muitos processos, dificultando a representação de conteúdo dos documentos. Nesse sentido, Dias e Naves (2007, p. 68), relata a complexidade na identificação de um assunto,

\footnotetext{
A noção de assunto de um documento é indeterminada, pois há casos em que é impossível, em princípio, decidir qual, de duas diferentes e igualmente precisas descrições, é a descrição do assunto, ou se o documento tem dois assuntos, ao invés de um. [...] Isso significa que há sérias dificuldades na escolha de um assunto que seja considerado o principal de um documento, deixando outros, que ele inclua, em plano secundário.
}

Dessa maneira, os editores dos periódicos devem atentar da necessidade de ficar alertas para a busca de uma padronização dos termos representativos do conteúdo temático do texto. Isso pode ser resolvido com a utilização de vocabulário controlado na indexação das palavras-chave. Conforme NBR 6028 (2003, p. 1), "Palavra representativa do conteúdo do documento, escolhida, preferentemente, em vocabulário controlado".

Após coleta de dados referentes à titulação dos autores, restou evidenciado que em vários artigos não existiam essas informações. Necessário esclarecer, portanto, que para a confecção da Tabela 4 "Titulação dos Autores dos Artigos", foram computados somente os dados fornecidos pelos autores.

Cumpre esclarecer que, se um determinado autor escreveu mais de uma vez no ano, ou mesmo em diversos anos, sua formação foi considerada, nas diversas vezes observadas. Sendo que em algumas ocasiões, um determinado autor elevou o percentual de alguma titulação em razão dos diversos artigos publicados.

Como se vê, houve um significativo acréscimo de autores que publicaram seus artigos na Revista Controle, levando-se em conta o ano de 2006 que apresentou um total de 6 artigos publicados em relação ao ano de 2012 que apresentou um total de 63 artigos publicados, correspondendo ao décuplo do número de artigos do ano de 2006. Esse crescimento observado decorreu, essencialmente, em razão da busca de uma 
melhor qualificação da Revista Controle junto ao sistema Qualis Periódicos da Coordenação de Aperfeiçoamento de Nível Superior (CAPES), nesse período.

Outrossim, convém destacar o percentual médio de autores com titulação de especialista, mestre e doutor, no período de 2005 a 2016, cujos percentuais correspondem à 21,21 \%, 18,96\% e 6,54\%, respectivamente. Merece nota o fato de que o elevado percentual dos autores com titulação de especialista em relação às titulações de mestre e doutor, o que permite aduzir acerca da dificuldade de acesso às pósgraduações stricto sensu no país. Contudo, percebe-se um percentual considerável de mestre, enquanto o percentual de doutor mantém-se significativamente menor. Considerando às variáveis de cada ano, percebe-se um aumento gradativo de mestre, mestrando e doutor. Isso reflete uma maior qualificação no meio acadêmico, pois se sabe que os autores procuram os periódicos com maior qualidade para submeter seus manuscritos.

Tabela 4 - Titulação dos autores dos artigos

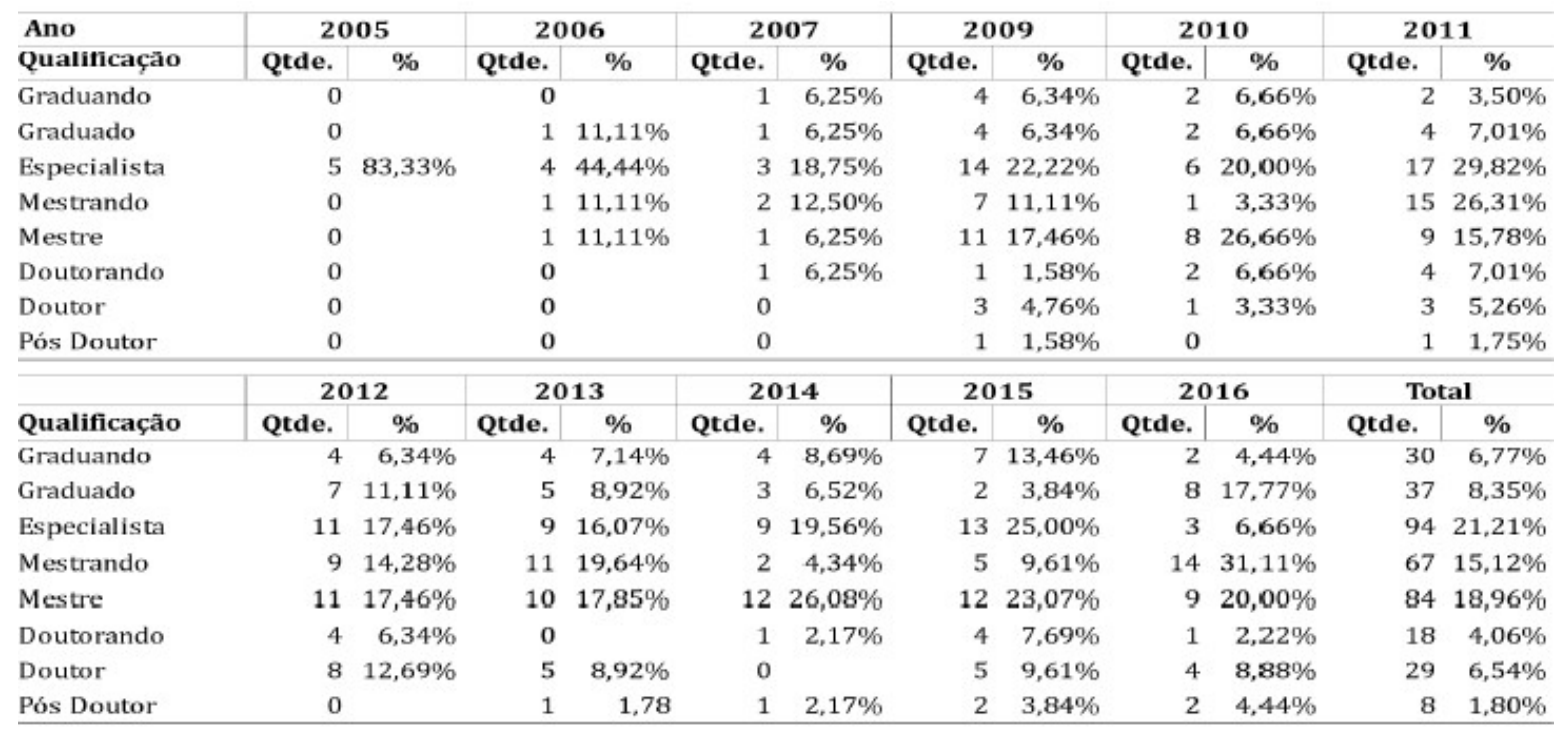

Fonte: Elaborada pelos autores.

Conforme se vê na Tabela 5, a quantidade de autores dos artigos publicados na Revista Controle, vinculados ao Tribunal de Contas do Estado do Ceará, iniciou com um percentual de 100\% de vinculação, entretanto, ao final de 2016, esse percentual foi reduzido para 4,76\%. Contudo, considerando o período de 2005 a 2016, obteve-se uma média percentual de vinculação $21,32 \%$. 
Desse modo, evidencia-se o crescente interesse de autores vinculados a instituições externas em publicarem seus artigos na Revista Controle, indicando, portanto, de forma clara sua exogenia, que retrata sua reputação acadêmica, tanto em nível nacional quanto internacional. Esses números trazem à tona que, a partir de 2009, a Revista Controle atingiu um critério de, pelo menos, $75 \%$ de exogenia, garantindo dessa maneira um nível de alto impacto no meio acadêmico, pois avançou externamente na academia.

Esse fato é considerado fundamental para a avaliação do Qualis Periódicos da Coordenação de Aperfeiçoamento de Nível Superior (CAPES), que elege esse critério para sua conceituação, uma vez que cada área de avaliação estabelece seus critérios de percentuais de exogenia.

Tabela 5 - Percentual de autores vinculados à instituição

\begin{tabular}{ccccc}
\hline Ano & V. No. & $\begin{array}{c}\text { Total de } \\
\text { Autores }\end{array}$ & $\begin{array}{c}\text { Total de Autores } \\
\text { Vinculados }\end{array}$ & $\begin{array}{c}\text { \% de Autores } \\
\text { Vinculados }\end{array}$ \\
\hline 2005 & v. 5, n. 2 & 6 & 6 & $100,00 \%$ \\
2006 & v. 6, n. 1 & 10 & 5 & $50,00 \%$ \\
2007 & v. 6, n. 2 & 16 & 7 & $43,75 \%$ \\
2009 & v. 7, n. 1 & 35 & 7 & $20,00 \%$ \\
2009 & v. 7, n. 2 & 28 & 5 & 17,85 \\
2010 & v. 8, n. 1 & 30 & 5 & 16,66 \\
2011 & v. 9, n. 1 & 24 & 2 & 8,33 \\
2011 & v. 9, n. 2 & 32 & 2 & 6,25 \\
2012 & v. 10, n. 1 & 34 & 8 & 23,52 \\
2012 & v. 10, n. 2 & 28 & 4 & 14,28 \\
2013 & v. 11, n. 1 & 27 & 1 & 3,7 \\
2013 & v. 11, n. 2 & 29 & 0 & 0 \\
2014 & v. 12, n. 1 & 23 & 5 & 21,73 \\
2014 & v. 12, n. 2 & 23 & 4 & 17,39 \\
2015 & v. 13, n. 1 & 28 & 2 & 7,14 \\
2015 & v. 13, n. 2 & 25 & 4 & 16 \\
2016 & v. 14, n. 1 & 24 & 3 & 12,5 \\
2016 & v. 14, n. 2 & 21 & 1 & 4,76 \\
\hline
\end{tabular}

Fonte: Elaborada pelos autores.

Conforme se vê na tabela 6, observa-se com relação ao número de páginas desses artigos, que os mesmos apresentaram em média 18,05 páginas, tendo o menor artigo apresentado 6 páginas (v. 5, no2, 2005) e o maior, 27 páginas (v. 7, no 1, 2009).

Vale ressaltar, que, conforme a (CAPES, 2007), os artigos, capítulos e trabalhos completos devem ter 7 páginas ou mais e os livros (textos na íntegra), 70 páginas ou mais para serem contabilizados em anais. 
Observa-se que os números (v.5, no2, 2005) e (v. 6, n. 1, 2006), não atenderam aos requisitos de publicação da Revista Controle, no quesito mínimo de 10 páginas; e os números (v. 7, n. 1, 2009), (v. 8, n. 1, 2010), (v. 9, n. 1, 2011) e (v. 10, n. 1, 2012), também, não cumpriram as exigências do número máximo de 20 páginas. Nesse sentido, os editores necessitam ser criteriosos, conforme as normas de submissão fixadas e aprovar, somente, as publicações que estiverem em conformidade com essas regras, garantindo, portanto, a qualidade editorial do periódico.

Portanto, fica claro que essas análises refletem em números os requisitos já definidos, que, às vezes, são atendidos, outras vezes, não são observadas. Fatos esses, que numa representação estatística são perceptíveis.

Tabela 6 - Quantidade de páginas por artigo

\begin{tabular}{|c|c|c|c|}
\hline VOL., NUM. E ANO & $\begin{array}{l}\text { TOTAL DE } \\
\text { ARTIGOS }\end{array}$ & $\begin{array}{c}\text { TOTAL DE } \\
\text { PÁGINAS PELO } \\
\text { TOTAL DE } \\
\text { ARTIGOS }\end{array}$ & MÉDIA \\
\hline V. 5, n. 2, (2005) & 6 & 57 & 9,5 \\
\hline V. 6,n. 1, (2006) & 8 & 50 & 6,25 \\
\hline v. 6, n. 2, (2007) & 14 & 94 & 6,71 \\
\hline V. 7, n. 1, (2009) & 27 & 402 & 14,88 \\
\hline V. 7, n. 2, (2009) & 20 & 391 & 19,55 \\
\hline V. 8, n. 1, (2010) & 23 & 411 & 17,86 \\
\hline V. 9, n. 1, (2011) & 21 & 363 & 17,28 \\
\hline V. 9, n. 2, (2011) & 19 & 388 & 20,42 \\
\hline V. 10, n. 1, (2012) & 21 & 410 & 19,52 \\
\hline V. 10, n. 2, (2012) & 19 & 382 & 20,1 \\
\hline V. 11, n. 1, (2013) & 20 & 340 & 17 \\
\hline V. 11, n. 2, (2013) & 17 & 303 & 17,82 \\
\hline V. 12, n. 1, (2014) & 16 & 258 & 16,12 \\
\hline V. 12, n. 2, (2014) & 18 & 327 & 18,16 \\
\hline V. 13, n. 1, (2015) & 19 & 396 & 20,84 \\
\hline V. 13, n. 2, (2015) & 15 & 339 & 22,6 \\
\hline V. 14, n. $1,(2016)$ & 11 & 257 & 23,36 \\
\hline V. 14, n. $2,(2016)$ & 13 & 373 & 28,69 \\
\hline ANO & $\begin{array}{l}\text { SOMA } \\
\text { (TOTAL DE } \\
\text { ARTIGOS) }\end{array}$ & $\begin{array}{l}\text { SOMA(TOTAL DE } \\
\text { PAGINAS PELO } \\
\text { TOTAL DE } \\
\text { ARTIGOS) }\end{array}$ & $\begin{array}{l}\text { MÉDIA } \\
\text { TOTAL }\end{array}$ \\
\hline $2005-2016$ & 307 & 5541 & 18,05 \\
\hline
\end{tabular}

Fonte: Elaborada pelos autores (2018). 


\section{CONCLUSÃO}

O referido estudo realizou uma análise bibliométrica dos artigos publicados na Revista Controle, no período de 2005 a 2016, para tanto, utilizou-se das técnicas de análise bibliométrica para medir a produção científica da Revista Controle, bem como contribuir para a melhoria do periódico, permitindo que o mesmo seja sucessivamente melhor avaliado pelo Qualis Periódicos da Coordenação de Aperfeiçoamento de Nível Superior (CAPES), tendo em vista permitir aos profissionais das áreas pertinentes disporem de mais um periódico de excelência de qualidade.

Os resultados apresentados nessa análise confirmam a importância que os estudos bibliométricos demonstram, ao identificar indicadores com base em um estudo feito, a partir de um determinado periódico, uma vez que a utilização da bibliometria pode ser considerada um tratamento metodológico informacional sobre a produção do conhecimento nas diversas áreas. Os indicadores selecionados para a consecução da análise bibliométrica desse estudo foram:

- mensurar o quantitativo de artigos nos anos de 2005 a 2016, por volume, número e ano de publicação;

- classificar os artigos por área de conhecimento;

- descobrir quais as palavras-chave mais utilizadas pelos autores dos artigos;

- conhecer os autores de artigos quanto à titulação;

- conhecer os autores de artigos em relação à vinculação institucional;

- averiguar o número médio de páginas por artigo.

Pontos de destaque no que se refere ao objetivo 1:

- A média anual de publicações no período foi de aproximadamente 28 artigos. Verificou-se que houve um crescimento de 450\% no número de publicações, considerando-se o menor número (6) referente ao ano de 2005, em relação ao maior (27) referente ao ano de 2009.

No quesito da periodicidade, observou-se que esse teve algumas lacunas de publicação, gerando provavelmente problemas na qualificação pelas entidades 
avaliadoras, pois esse critério é essencial para uma publicação periódica na busca pela excelência. Outro ponto, a ser destacado é a definição na sua política editorial da quantidade de artigos a serem publicados por edição, de acordo com o foco almejado. Senão pode comprometer sua avaliação e indexação em bases de dados. Contudo, o periódico de maneira geral obteve êxito no crescimento de artigos publicados.

Pontos de destaque em relação ao objetivo 2:

- Dos 307 artigos publicados na Revista Controle, 39,41\% estão categorizados na área de conhecimento "Administração Pública"; enquanto 30,61\% do total de artigos estão categorizados na área de conhecimento "Direito Público"; seguido de 2,29\% na área de "Economia"; e, por fim, 1,95\% em "Serviços Urbanos e Regionais", totalizando um percentual de 76,22\% na grande área de Ciências Sociais Aplicadas.

No que se refere à área de conhecimento, o estudo revelou o compromisso deste periódico com diversas temáticas, embora, evidenciou-se nos artigos publicados que seu foco temático atende o perfil editorial que é as áreas da administração pública e direito público. Dessa forma, sua política editorial reforça o compromisso de publicar temáticas que contribuam para o crescimento científico da área do controle externo.

O estudo aponta que os resultados, refletem as suas áreas de avaliação no sistema Qualis Periódicos da Coordenação de Aperfeiçoamento de Nível Superior (CAPES), na qual recebeu classificação B4, na área de Administração Pública e de Empresas, Ciências Contábeis e Turismo, no quatriênio (2013-2016, bem como em Planejamento Urbano e Regional/Demografia com nota semelhante. Vale ressaltar que na área do Direito, Economia e Interdisciplinar, sua avaliação encontra-se com estrato C.

Nesse sentido, os editores podem se apropriar dos dados bibliométricos para monitorar os campos do conhecimento do seu periódico, pois ele permite avaliar quais as áreas de maior incremento e as periféricas, podendo reavaliar seu perfil editorial.

Pontos de destaque quanto ao objetivo 3:

- Os 307 artigos selecionados apresentam 1085 palavras-chave, ou seja, uma média de 3,53 palavras-chave por artigo. Considerando que um total de 56 artigos não apresentaram palavras-chave, deve-se ressaltar que a média de 4,32 palavras- 
chave foi obtida levando-se em conta o total de 251 artigos que apresentaram palavras-chave.

Pontua-se que as palavras-chave retratam as principais áreas do conhecimento: administração pública e direito, demonstrando dessa forma uma correlação. Assim a média das palavras-chave condiz com as normas de publicação do periódico. Percebe-se que há termos semelhantes, situação que pode ser minimizada com o uso de vocabulário controlado. Reflexo disso é a grande quantidade de termos únicos. Configura-se, assim, uma necessidade de padronização e revisão dos termos para a qualidade da indexação no periódico.

Pontos de destaque com relação ao objetivo 4:

- Outrossim, convém destacar o percentual médio de autores com titulação de especialista, mestre e doutor, no período de 2005 a 2016, cujos percentuais correspondem à $21,21 \%, 18,96 \%$ e 6,54\%, respectivamente.

Nesse caso, refere-se a busca pela qualificação dos autores cujo impacto reflete, significativamente, na qualidade dos artigos publicados. Nessa perspectiva, deve-se procurar despertar o interesse de autores vinculados aos programas de pós-graduação, em razão de ser um grupo seleto.

Certamente, a melhor classificação do periódico poderá atrair autores com maiores titulações, nos próximos anos.

Pontos de destaque no âmbito ao objetivo 5:

- A quantidade de autores dos artigos publicados na Revista Controle, vinculados ao Tribunal de Contas do Estado do Ceará, iniciou com um percentual de 100\% de vinculação, entretanto, ao final de 2016, esse percentual foi reduzido para 4,76\%. Contudo, considerando o período de 205 a 2016, obteve-se uma média percentual de vinculação 21,32\%;

- Desse modo, evidencia-se o crescente interesse de autores vinculados a instituições externas em publicarem seus artigos na Revista Controle, indicando, portanto, de forma clara a exogenia, que retrata sua reputação acadêmica, tanto em nível nacional quanto internacional. 
Quanto à diversidade de autores (443) envolvidos na publicação dos 307 artigos publicados, no período de 2005 a 2016 da Revista Controle, pode-se concluir que este número elevado de autores caracterizam, de forma preponderante, que há uma preocupação com a busca pela diversificação, pelo nível de excelência de suas publicações e pontos de vista. Infere-se que a exogenia é fundamental para a maior relevância, qualificação e indexação em bases de dados, tornando um critério essencial para os periódicos que querem aumentar sua qualidade editorial. Uma alternativa para os periódicos sobressaírem na era das redes sociais é utilizar das ferramentas de comunicação como vídeo abstract, infográfico, buscando aumentar sua visibilidade.

Pontos de destaque em relação ao objetivo 6:

- observa-se com relação ao número de páginas desses artigos, que os mesmos apresentaram em média 18,05 páginas, tendo o menor artigo apresentado 6 páginas (v. 5, n. 2, 2005) e o maior, 27 páginas (v. 7, n. 1, 2009);

- conforme a (CAPES, 2007), os artigos, capítulos e trabalhos completos devem ter 7 páginas ou mais e os livros (textos na íntegra), 70 páginas ou mais para serem contabilizados em anais.

Em relação ao número de páginas deve ser um critério padronizado pelas normas de publicação do periódico. Contudo, verifica-se que esse critério básico, muitas das vezes, não são respeitadas pelos autores. Portanto, os editores, devem filtrar essas submissões, solicitando as adequações necessárias. Embora, seja recente, a atuação desta publicação no campo científico, a qual teve início em 2005, os resultados apresentados nessa análise corroboram o potencial que os estudos bibliométricos possuem, pois permitiu apontar a evolução da Revista Controle no meio científico.

Por fim, faz-se necessária a continuidade desta investigação, de modo a permitir que sejam caracterizados os demais indicadores bibliométricos, bem como a publicação de artigos, cuja metodologia contemple a utilização de bases de dados com amostras de representatividade nacional e internacional e os fatores de impacto dos artigos no meio científico. 


\section{REFERÊNCIAS}

ASSOCIAÇÃO BRASILEIRA DE NORMAS TÉCNICAS. NBR 6028: resumos. Rio de Janeiro, 2003. 3 p.

ALVARADO, Rubén Urbizagástegui. A Bibliometria no Brasil. Ciência da

Informação, [S.l.], v. 13, n. 2, dez. 1984. Disponível em: http://revista.ibict.br/ciinf/article/view/20 0. Acesso em: 09 nov. 2017.

BAPTISTA, Ana Alice et al. Comunicação científica: o papel da open archives initiative no contexto do acesso livre. Encontros Bibli: revista eletrônica de biblioteconomia e ciência da informação, Florianópolis, num. Especial 1, p. 1-17, 2007. Disponível em: http://www.redalyc.org/articulo.oa?id=147 20411010. Acesso em: 10 ago. 2017.

BRESSANE, Julia Miranda; OHIRA, Maria Lourdes Blatt. Evolução e avaliação da Revista ACB: Biblioteconomia em Santa Catarina enquanto fonte de pesquisa (20002004). Revista ACB, [S.l.], v. 12, n. 1, p. 5-7, mar. 2007. Disponível em: https://revista.acbsc.org.br/racb/article/vie w/491/632. Acesso em: 01 nov. 2017.

CUNHA, Murilo Bastos da. Dicionário de biblioteconomia e arquivologia. Brasília, DF: Briquet de Lemos/Livros, 2008. 451 p.

DIAS, Eduardo Wense; NAVES, Madalena Martins Lopes. Análise de assunto: teoria e prática. Brasília: Editora Thesaurus, 2007.

DAVYT, Amilcar; VELHO, Léa. A avaliação da ciência e a revisão por pares: passado e presente. Como será o futuro? Hist. cienc. saude-Manguinhos [online], v. 7, n.1, p. 93116, 2000.

DROESCHER, Fernanda Dias; SILVA, Edna Lucia da. O pesquisador e a produção científica. Perspect. Ciênc. Inf., Belo Horizonte, v. 19, n. 1, p. 170-189, mar. 2014. Disponível em: http://www.scielo.br/scielo.php?script=sci_ arttext\&pid=S1413- 99362014000100011\&lng=pt\&nrm=iso.

Acesso em: 26 jul. 2018.

GONZÁLEZ DE GOMEZ, Maria Nélida. Da questão da validade ao julgamento de valor: mediação informacional da avaliação científica. In: ENCONTRO NACIONAL DE PESQUISA EM CIÊNCIA DA INFORMAÇÃO, 15., 2014, Belo Horizonte. Anais... Belo Horizonte: UFMG, 2014.

KURAMOTO, Hélio. Acesso livre à informação científica: novos desafios. Liinc em Revista, Rio de Janeiro, v. 4, n. 2, p. 154-157, set. 2008. Disponível em:

http://revista.ibict.br/liinc/article/view/31 71/2834. Acesso em: 01 nov. 2017.

KURAMOTO, Hélio. Informação científica: proposta de um novo modelo para o Brasil. Ci. Inf., Brasília , v. 35, n. 2, p. 91-102, ago. 2006. Disponível em:

http://www.scielo.br/scielo.php?script=sci_ arttext\&pid=S0100-

$19652006000200010 \& \operatorname{lng}=$ en\&nrm=iso.

Acesso em: 01 nov. 2017.

MIRANDA, Dely Bezerra de; PEREIRA, Maria de Nazaré Freitas. O Periódico Científico como Veículo de Comunicação: uma Revisão de Literatura. Ciência da Informação, [S.l.], v. 25, n. 3, dec. 1996. Disponível em: http://revista.ibict.br/ciinf/article/view/63 6. Acesso em: 01 nov. 2017.

MUELLER, Suzana Pinheiro Machado. A ciência, o sistema de comunicação científica e a literatura científica. In: CAMPELLO, Bernadete Santos; CENDÓN, Beatriz Valadares; KREMER, Jeannette Marguerite (Org.). Fontes de informação para pesquisadores e profissionais. Belo Horizonte: Ed. UFMG, 2000. p. 21-34.

RUSSO, Mariza; SANTOS, Eliana Taborda G.; SANTOS, Maria José Veloso da Costa. Produção científica brasileira: da comunicação à recuperação via WEB. In: FÓRUM NACIONAL DE PADRONIZAÇÃO E DIVULGAÇÃO DA PRODUÇÃO CIENTÍFICA, 2001, Fortaleza. Anais... Disponível em: 
www.sibi.ufrj.br/trab_mariza_ago2001.doc. Acesso em: 09 nov. 2017.

SOLANO, Viviane de Oliveira; GUERRA, Fernando César Gonçalves. Análise bibliométrica da Revista Perspectivas Gestão \& Conhecimento (PG\&C): período 2011-2013. In: ENCONTRO BRASILEIRO DE BIBLIOMETRIA E CIENTROMETRIA, 4., 2014, Recife. Anais... 2013. p. 1-8. Disponível em: https://www.bracpi.inf.br/index.php/article /download/27217. Acesso em: 26 jul. 2018.

SOUZA, Maria Naires Alves; COSTA, Rosane Maria. A informação científica de acesso aberto na Universidade Federal do Ceará: contribuições da biblioteca universitária.

Revista Brasileira de Biblioteconomia e Documentação, Brasília, v. 13, n. esp. CBBD, p. 960-977, 2017. Disponível em: https://rbbd.febab.org.br/rbbd/article/view /791/857. Acesso em: 09 nov. 2017.

SOUZA, Pereira Salles de. Publicação de revistas científicas na Internet. Rev. Bras.

Cir. Cardiovasc., São José do Rio Preto , v. 21, n. 1, p. 24-28, mar. 2006 . Disponível em: http://www.scielo.br/scielo.php?script=sci_ arttext\&pid=S010276382006000100006\&lng=en\&nrm=iso. Acesso em: 06 nov. 2017.

SPINAK, E.; PACKER, A. 350 anos de publicação científica: desde o "Journal des Sçavans" e "Philosophical Transactions" até o SciELO [online]. SciELO em Perspectiva, 2015. Disponível em: http://blog.scielo.org/blog/2015/03/05/35 0 -anos-de-publicacao-cientifica-desde-o- journal-des-scavans-e-philosophicaltransactions-ate-o-scielo. Acesso em: 06 nov. 2017.

TARGINO, Maria das Graças. Comunicação científica: uma revisão de seus elementos básicos. Informação \& Sociedade: Estudos, João Pessoa, v. 10, n. 2, p. 1-27, 2000. Disponível em:

http://www.periodicos.ufpb.br/ojs/index.ph p/ies/article/view/326/248. Acesso em: 09 nov. 2017.

VANTI, Nadia Aurora Peres. Da bibliometria à webometria: uma exploração conceitual dos mecaniscos utilizados para medir o registro da informação e a difusão do conhecimento. Ciência da Informação, Brasília, v. 31, n. 2, p. 152-162, maio/ago. 2002. Disponível em: www.scielo.br/pdf/ci/v31n2/12918.pdf. Acesso em: 09 nov. 2017.

VANTI, Nadia Aurora Peres. Indicadores web e sua aplicação à produção científica disponibilizada em revistas eletrônicas. In: FERREIRA, Sueli Mara Soares Pinto; TARGINO, Maria das Graças (org.). Acessibilidade e visibilidade de revistas científicas eletrônicas. São Paulo: SENAC; São Paulo: Cengage Learning, 2010. p. 175212.

WEITZEL, S. R. Fluxo da informação científica. In: POBLACION, D. A.; WITTER, G. P.; SILVA, J. F. M. (org.). Comunicação \& produção científica: contexto, indicadores e avaliação. São Paulo: Angellara, 2006. cap. 3, p. 83-114. 